\title{
Neurochemical and Hormonal Contributors to Compulsive Sexual Behavior Disorder
}

\author{
Andreas Chatzittofis ${ }^{1,2}(0) \cdot$ Adrian Desai E. Boström $^{2,3} \cdot$ Josephine Savard $^{2} \cdot$ Katarina Görts Öberg $^{4} \cdot$ Stefan Arver $^{4}$. \\ Jussi Jokinen ${ }^{2,5}$
}

Accepted: 21 November 2021 / Published online: 6 January 2022

(c) The Author(s) 2022

\begin{abstract}
Purpose of Review Compulsive sexual behavior disorder has been recently included in the 11th revision of the International Classification of Diseases (ICD-11), and the possible contribution of neurochemical and hormonal factors have been reported. However, relatively little is known concerning the neurobiology underlying this disorder. The aim of this article is to review and discuss published findings in the area.

Recent Findings Evidence suggests that the neuroendocrine systems are involved in the pathophysiology of compulsive sexual behavior. The hypothalamus-pituitary adrenal axis, the hypothalamus-pituitary-gonadal axis, and the oxytocinergic system have been implicated.

Summary Further studies are needed to elucidate the exact involvement of neuroendocrine and hormonal systems in compulsive sexual behavior disorder. Prospective longitudinal studies are particularly needed, especially those considering co-occurring psychiatric disorders and obtaining hormonal assessments in experimental circumstances with appropriate control groups.
\end{abstract}

Keywords Compulsive sexual behavior disorder $\cdot$ Hypersexuality $\cdot$ Sexual addiction $\cdot$ HPG axis $\cdot$ HPA axis $\cdot$ Oxytocin

\section{Introduction}

Human sexual behavior is complicated, essential from an evolutionary aspect, and is closely related to both physical and mental health. There is a bidirectional relationship

This article is part of the Topical Collection on Sex Addiction

Andreas Chatzittofis

chatzittofis.andreas@ucy.ac.cy

1 Medical School, University of Cyprus, Palaios Dromos Lefkosias Lemesou No.215/6 2029 Aglantzia, 1678 Nicosia, Cyprus

2 Department of Clinical Sciences/Psychiatry, Umeå University, Umeå, Sweden

3 Neuropaediatric Unit, Department of Women's and Children's Health, Karolinska Institutet, Stockholm, Sweden

4 Department of Medicine, Karolinska Institutet, Karolinska University Hospital, Stockholm, Sweden

5 Department of Clinical Neuroscience/Psychiatry, Karolinska Institutet, Stockholm, Sweden between psychiatric symptoms, psychiatric disorders, and sexual symptoms [1]. Indeed, sexual symptoms such as low sexual drive might be a symptom of depression, whereas high sexual engagement could reflect hypomanic or manic behavior. Moreover, Grant et al. reported that $24.9 \%$ of 293 individuals with a primary diagnosis of obsessive-compulsive disorder (OCD) experienced sexual obsessions; however, individuals with and without sexual obsessions demonstrated similar quality of life and social functioning [2]. People with Parkinson's disease also may exhibit hypersexual behavior when treated with dopamine agonists [3].

The conceptualization of hypersexuality as a distinct entity has been a matter of debate $[1,4,5]$. Different conceptual models have been proposed such as compulsive sexual behavior, sexual addiction, sexual impulsivity, and sexual desire dysregulation $[1,6,7]$.

In 2010, the term "hypersexual disorder" (HD) was proposed by Kafka [1] as a potential diagnosis to be included in the fifth edition of the Diagnostic and Statistical Manual of Mental Disorders (DSM 5) [1]. Kafka defined HD as a nonparaphilic sexual desire disorder including features of impulsivity, sexual desire dysregulation, sexual addiction, 
and compulsivity. This proposed disorder was considered to be a maladaptive response to dysphoric affective states and life stressors. Although the proposed criteria were evaluated and showed high validity and reliability [8], the diagnosis was not included in the DSM-5. However, a related condition, compulsive sexual behavior disorder (CSBD), was included in the 11th revision of the International Classification of Diseases (ICD-11) [9]. The CSBD criteria include a persistent pattern of failure to control intense, repetitive sexual impulses or urges, resulting in repetitive sexual behavior over an extended period of time. The disorder is associated with marked distress or impairment in important areas of functioning such as personal, family, social, educational, and occupational. In addition, the person may have made numerous unsuccessful efforts to reduce or to control the repetitive sexual behavior and the person continues the repetitive sexual behavior regardless of adverse consequences such as repeated relationship disruption, occupational consequences, and negative impact on health. Finally, the person persists with the sexual behavior even when no or minimal satisfaction is derived from [10].

CSBD frequently co-occurs with mood, anxiety, substance use, and impulse control disorders [7, 8, 11-13]. Although there are methodological issues and ongoing debate $[14,15]$ regarding the validity as well as the diagnostic criteria, CSBD seems to affect predominately men compared to women, with reported rates between 3 and $6 \%$ of the population $[1,13,16]$. By contrast, and in support of CSBD as a separate entity, evidence suggests that women are as likely as men to report sexual obsessions in OCD [2]. The debate regarding the conceptualization of CSBD is ongoing and hopefully, the inclusion of CSBD in the ICD-11 will promote more research in elucidating the phenomenology and pathophysiology of the disorder [9].

\section{Neurobiology, Neurochemical, and Hormonal Contributions}

Although many cultural and societal factors may influence human sexual behavior, biological systems have a key role and are essential to understanding sexual behavior. Biological systems involved in human sexual behavior include limbic, cortical, and neuroendocrine systems [17-19]. From a physiological perspective, sexual response is controlled by monoamines (such as noradrenaline, dopamine, and serotonin), acetylcholine, neuropeptides, glutamate, and GABA [20-23]. In addition, endocrine diseases such as hypogonadism, hyperprolactinemia, and extragonadal endocrinopathies may impact sexual function [24]. Brain lesions especially in frontal and temporal lobes as well as in the Kluver-Bucy syndrome have been linked to hypersexual behavior [13]. Regarding neuroendocrine systems and sexual behavior, much research has focused on reduced sexual behavior such as in the case of hypogonadism, linked to hypoactive sexual desire and erectile dysfunction, with only limited research on hypersexuality [24]. Recent efforts have started to elucidate different pathophysiological aspects of CSBD, mainly through neuroimaging studies [25].

Precise pathophysiological mechanisms, including underlying CSBD and neurochemical alternations, remain largely unknown. In this short review, we aim to present and discuss the most relevant studies that focus on endocrine systems involved in CSBD, especially those exploring the hypothalamus-pituitary adrenal (HPA) and hypothalamuspituitary-gonadal (HPG) axes and the oxytocinergic system.

\section{HPA Axis}

Dysregulation of the HPA axis, evidenced by the dexamethasone suppression test (DST), has been linked to suicidality and reported in different psychiatric disorders including depression and addiction [26]. Poor regulation of stress involving the HPA axis contributes to addictions. More specifically, the corticotropin-releasing factor (CRF) is involved with increased adrenocorticotropic hormone (ACTH) levels; thus a hyperactive HPA axis may result from prolonged drug use and consequent drug withdrawal [27, 28]. This new, allostatic state is critical to induce craving and relapse.

Earlier research on the stress system and sexual behavior has reported mixed results with studies suggesting both an inhibitory and facilitating role for cortisol on sexual behavior [17]. The majority of previous studies investigated changes of the HPA axis as a result of sexual behavior. It was reported that plasma cortisol levels were both unaffected during film-induced sexual arousal as well as during sexual arousal and orgasm in healthy volunteers [29, 30]. Later studies revealed a positive correlation between baseline salivary cortisol and sexual arousal, using an imagined sexual social situation exercise in healthy volunteers [17]. Nevertheless, there was no change in salivary cortisol due to sexual thoughts when compared to control conditions. Moreover, higher salivary cortisol reactivity was reported in participants with risk-taking sexual behavior using the Trier Social Stress Test [31]. However, the possible long-standing effects of hypersexual behavior on the function of the HPA axis were not investigated in these studies.

HPA axis was not explicitly investigated in CSBD until recently when we reported for the first time that DST nonsuppression status was significantly more prevalent in men with HD compared to healthy volunteers. In fact, hypersexual men had significantly higher DST ACTH plasma levels compared to healthy age-matched controls. In addition, hypersexual symptoms were inversely correlated with baseline cortisol plasma levels as well as with DST cortisol

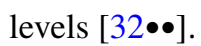


Possible confounders when investigating the HPA axis include psychiatric disorders such as depression and posttraumatic stress disorder (PTSD) and childhood adversity. Furthermore, hyperactivity of the HPA axis, shown through the dexamethasone non-suppression, has been related to severe melancholic depression with psychotic symptoms and suicide attempters [33-35]. Likewise, childhood adversity, especially sexual abuse, has been proposed to increase tendency for risky sexual behavior and CSBD $[36,37]$ and may have detrimental effects including psychopathology in adulthood. A suggested mechanism is through dysregulation of neurobiological systems such as the HPA axis, mediated through epigenetic changes such as DNA methylation [38-40]. Importantly, in our study, the results on the HPA axis were neither related to childhood adversity nor depres-

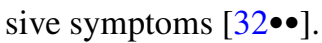

The same cohort of men with HD was further investigated in comparing epigenetic profiles in affected and control subjects. In this study, we reported that hypersexuality is associated with reduced levels of DNA methylation at the $\operatorname{cg} 23409074$ locus located 48 base pairs upstream of the transcriptional start site of the corticotropin-releasing factor $(\mathrm{CRH})[41 \bullet \bullet]$. In addition, in an independent cohort of healthy male subjects, methylation levels at this locus was demonstrated to be significantly positively correlated with $\mathrm{CRH}$ gene expression levels, providing preliminary evidence that the identified methylation shift in hypersexual subjects may be associated with alterations in gene expression patterns. Moreover, cg23409074 methylation levels were significantly correlated between blood and four different brain regions, suggesting the findings observed in whole blood could be related to pathophysiological brain mechanisms. $\mathrm{CRH}$ has a key role in stress regulation as well as addiction [42] and mediates the negative affective responses to stress and craving during drug withdrawal [27, 28]. Chronic use of drugs may maintain a hyperactive HPA axis with increased levels of stress hormones such as ACTH. Epigenetic factors linked CRH gene expression have also been reported in heroin self-administration in animal models [43], suggesting links between CSBD and substance addictions.

\section{HPG Axis}

The hypothalamus-pituitary-gonadal (HPG) axis is directly involved in sexual behavior with testosterone being essential for maintaining a healthy sexual life. The effects of testosterone are mediated through effects on motivation, emotion cognition, and autonomic responses [19, 44]. Testosterone may act directly or through the conversion to estradiol, with each binding to their respective receptors. However, the explicit role of the HPG axis in sexual behavior is complex and the relationship between androgens and sexual behavior seems to be bidirectional $[44,45]$.
In physiological studies, erotic visual stimulation, orgasm frequency, and sexual anticipation have altered testosterone levels [17]. In addition, previous experiences and the context and the nature of sexual stimuli may moderate effects on testosterone levels. For example, repeated exposure and previous experience of men to pornography have modulated the association of testosterone levels with sexual interest. More prior exposure increased the association of testosterone levels with sexual interest [46]. Thus, testosterone may act as motivation enhancer when repeated exposure has led to habituation. Finally, the majority of studies investigating testosterone were designed to measure hormone levels following sexual stimulus (i.e., watching erotic films, engaging in masturbation or coitus) without investigating longer-term effects or effects after prolonged exposure to sexual behavior such in the case of CSBD [47].

Furthermore, in hypogonadism, lower testosterone has been related to less behaviors and poorer functioning. Interestingly, testosterone supplementation has been reported to enhance sexual function, and although there is some support for increased libido, results remain mixed [48].

Despite limited research, antiandrogen therapy has been common in paraphilic patients and sexual-offending individuals [49]. Thus, not surprisingly, most studies on testosterone levels in clinical populations were of sexual-offending individuals in forensic settings. However, these studies provide seemingly contradictory results $[21,50]$. Additionally, a meta-analysis did not find group differences in testosterone levels in sexual-offending and non-sexual offending individuals. However, the authors report that differences might exist within subgroups of individuals, with perpetrators of child molestation demonstrating lower testosterone levels [50]. Although there is an overlap between sexual-offending individuals, patients, and those with CSBD, there are differences especially regarding antisocial and aggressive tendencies $[51,52]$.

Interestingly, there was no studies of CSBD in non-forensic settings until recently, when we reported that male CSBD patients did not differ in plasma testosterone levels compared with healthy volunteers [53••]. However, testosterone plasma levels and measures of compulsive sexual behavior (Sexual Compulsivity Scale (SCS) and Hypersexual Disorder: Current Assessment Scale (HD: CAS)) were positively correlated in CSBD patients. Thus, higher testosterone levels were related to more sexually compulsive behavior, sexual preoccupations, and sexually intrusive thoughts. Indeed, correlations between levels of androgens, especially testosterone and measurements of well-being, and sexual functions have been previously reported. This has also been reported with measurements of hypersexual symptoms such as SCS and HD: CAS in hypersexual patients. However, these scales and especially SCS measure specific aspects of hypersexuality, compulsive sexual symptoms such as 
behavior, preoccupations, and intrusive thoughts. Moreover, it was first developed for the assessment of high-risk sexual behaviors such as high number of different sexual partners, no use of protective measures during intercourse, sexually transmitted diseases, and drugs and alcohol use prior to sex $[1,54,55]$.

Luteinizing hormone ( $\mathrm{LH})$ acts as the key regulator of gonadal hormones. However, studies of LH, like those of testosterone, have reported mixed results with respect to sexual behavior. Arguably, most relevant are physiological studies and studies in forensic settings. A study of sexual arousal reported it had a postponing effect on the second peak of LH after the arousal and concurrently increased the height of the peak [47]. Previous studies of LH plasma levels in patients with erectile dysfunction reported lower bioactive/immunoactive LH ratios compared to healthy men. Interestingly, this was reversed after the recommencing of sexual activity [56].

Additionally, studies of sexual offending individuals' long-term recidivism reported that follicle-stimulating hormone (FSH) and LH levels positively correlated with hostility and were better predictors for recidivism than testosterone [57]. It was proposed that a dysregulation of LH is evident in a subgroup of sexual-offending individuals with poor downregulation. Further, among men with pedophilia, infusion of $100 \mathrm{mcg}$ of synthetic LH-releasing hormone demonstrated greater increases in LH levels compared with that in both men with non-pedophilic paraphilias and men with no sexual disorders [58]. Of note, there was no difference in basal LH plasma levels between the groups. Arguably, the most relevant study with a comparable population to CSBD patients (i.e., non-paraphilic hypersexual men), investigated the long-acting analog of gonadotropin-releasing hormone, triptorelin [59]. The authors reported normal baseline levels of testosterone and LH [59]. In the study, the number of sexual attempts was reduced as were LH and testosterone levels after treatment. However, no control group was included.

In our study investigating the HPG axis, we found higher LH plasma levels in men with CSBD compared to those without [53••]. However, LH levels in both men with and without CSBD were within the reference range. As LH levels were in the normal range, these results should be interpreted with caution.

It is important to mention that different endocrine systems including the HPA and HPG axes interact, with the HPA axis having an inhibitory effect on LH suppression. According to the dual hormone hypothesis, the effect of testosterone on risk-taking behaviors and aggression are moderated by cortisol levels; i.e., testosterone is associated with risk taking in the presence of low cortisol $[60,61]$. In the same line, as mentioned above, we reported a negative correlation between SCS and cortisol levels and a positive correlation between SCS and testosterone levels in CSBD men [32••, 53••]. There are also other factors besides stress and cortisol that might moderate associations between testosterone and sexual behavior. These factors include previous sexual experience, gender, and aspects of desire [61, 62].

\section{Oxytocin}

The neuropeptide oxytocin, involved in reproduction, prosocial, stress regulation, affiliative behavior, and addiction, has recently been reported to be involved in sexual behavior [63-67]. Regarding sexual behavior, oxytocin is involved in physiological reactions with increased release during penile erection and ejaculation [68-70]. In addition, plasma oxytocin levels were associated with orgasm intensity, and naloxone-induced inhibition of oxytocin resulted in a decrease in sexual satiety, independent of ejaculation [71-73].

Regarding hypersexual disorder/CSBD, we presented the first epigenetic study performed in a hypothesis-free and thereby unbiased approach. This study demonstrated both epigenetic and transcriptional involvement of microRNA-4456 in hypersexual disorder. In silico analyses provided preliminary evidence indicating that the identified microRNA regulates genes that are preferentially expressed in the brain and involved in the oxytocin signaling pathway, previously implicated in hypersexual disorder [74••]. Specifically, the study reports differential methylation of two CpG sites linked to MIR708 (cg18222192, hypomethylated) and MIR4456 (cg01299774, hypermethylated) in subjects with hypersexual disorder compared to that in healthy controls. MIR4456 was further demonstrated to be consistently differentially expressed in CSBD, using both univariate and multivariate analyses. Moreover, methylation levels of the cg01299774 site were inversely correlated with the expression levels of MIR4456, and there were disease state-dependent (i.e., CSBD-related) effects on the directions of the associations between methylation status and expression levels. Interestingly, cg01299774 was also hypermethylated in people with alcohol use disorder. In silico analyses suggested that the targets of MIR4456 include genes expressed in the hippocampus and amygdala and that are involved in the oxytocin signaling pathway.

Furthermore, preliminary data from our lab, for the first time, report higher oxytocin plasma levels in men with CSBD compared with those in healthy volunteers and that oxytocin levels are significantly positively correlated with CSBD symptom severity. This study was longitudinal, and CSBD patients exhibited a significant reduction in their oxytocin levels after following a manual-based group-administered cognitive behavioral therapy (CBT) program. In fact, the difference in oxytocin 
levels was significantly positively correlated with changes in compulsive sexuality symptom severity.

The results regarding the oxytocinergic system can be interpreted through oxytocin's inhibitory role on the activity of the HPA axis during exposure to stress. It was previously reported that the transcription of CRF is regulated by oxytocin receptor activity [75]. External oxytocin administration may reduce the cortisol response to stressful stimuli $[76,77]$. Oxytocin is also involved in some addiction models, reducing drug-seeking behavior and craving, effects purportedly driven by the actions of CRF [78, 79]. In addition, reported increased levels of oxytocin are in line with our previous findings of HPA axis dysregulation in men with CSBD [32••]. An alternative explanation would be the association of oxytocin and vasopressin in the regulation of impulsivity and pair bonding. Indeed, genetic variation of the oxytocin receptor gene was found to be important in pair-bonding in women [80, 81] and associated with borderline personality disorder $[82,83]$, a disorder characterized by severe impulsivity dysregulation.

\section{Other Systems}

There are also other neurobiological systems that are implicated in the regulation of sexual behavior and possibly CSBD. The inhibitory effects of prolactin on sexual behavior are well described [24, 63] and are proposed to result from low testosterone due to inhibition of gonadotropin secretion and low central dopamine as an indirect effect of hyperprolactinemia [24]. In addition, the cannabinoid system has gathered attention, and important interactions to key endocrine pathways, such as the HPG and HPA axes, have been reported [84-86]. Although arguably with contradictory results, the endocannabinoid system interacts with hormones such as estrogen in complex ways, inhibiting certain motivational processes including sexual desire. Thus, the endocannabinoid system exerts an inhibitory effect on the HPG axis. Additionally, cannabinoid agonists may interfere with social and sexual motivation [84].

Another potentially promising target is the opioid system. It is reported that patients on opioid maintenance therapy report negative effects on their sexuality, most commonly hypoactive sexual desire and low libido [87]. Regarding symptoms of CSBD, there were previous reports that an opioid receptor antagonist, naltrexone, might reduce urges and behaviors related with compulsive sexuality [88, 89]. Additional support comes from an open, pilot, feasibility study of 20 men with CSBD, finding a significant decrease on CSBD symptoms during treatment with naltrexone [90•].

\section{Conclusion}

We have presented recent findings regarding the involvement of key neuroendocrine systems including the HPA axis, the HPG axis, and the oxytocinergic system in CSBD. Although there are promising preliminary findings, the explicit involvement of these systems is far from elucidated. The inclusion of CSBD in the ICD-11 should help international research efforts both in diagnosis and treatment standardization as well as to provide more information on the pathophysiology of the disorder. Prospective case control studies in well-characterized CSBD patients, in both males and females, taking into account prior and current considerations such as substance use, obsessive-compulsive, and depressive disorders, PTSD, ADHD, history of childhood adversity, and sexual activity. Although forensic populations can be of great value, these should be well characterized to avoid possible confounders.

The evaluation and assessment of neurobiological correlates of CSBD should be done with caution. There are different features that might be important in the interpretation of results, most importantly as there is no definite consensus regarding the definition and phenomenology of the disorder. When investigating neurobiological systems, considering possible interactions between different neurobiological systems such as the HPA and HPG axes and the oxytocinergic system is important. Physiological variation should be taken into account, as well as the possible effect of sexual behavior on hormone levels. Regarding genetic and epigenetic studies, ideally these should include functional outcomes such as gene expression and hormone levels. Finally, the research domain criteria framework should be applied in imaging, molecular, genetic, and epigenetic studies to elucidate the pathophysiology of CSBD.

\section{Ethics Approval}

All reported studies/experiments with human or animal subjects performed by the authors have been previously published (except abovementioned preliminary data on oxytocin) and complied with all applicable ethical standards (including the Helsinki declaration and its amendments, institutional/national research committee standards, and international/national/institutional guidelines).

Funding Open access funding provided by Umea University.

\section{Declarations}

Conflict of Interest The authors declare no competing interests. 
Open Access This article is licensed under a Creative Commons Attribution 4.0 International License, which permits use, sharing, adaptation, distribution and reproduction in any medium or format, as long as you give appropriate credit to the original author(s) and the source, provide a link to the Creative Commons licence, and indicate if changes were made. The images or other third party material in this article are included in the article's Creative Commons licence, unless indicated otherwise in a credit line to the material. If material is not included in the article's Creative Commons licence and your intended use is not permitted by statutory regulation or exceeds the permitted use, you will need to obtain permission directly from the copyright holder. To view a copy of this licence, visit http://creativecommons.org/licenses/by/4.0/.

\section{References}

Papers of particular interest, published recently, have been highlighted as:

- Of importance

$\bullet$ Of major importance

1. Kafka MP. Hypersexual disorder: a proposed diagnosis for DSM-V. Arch Sex Behav. 2010;39(2):377-400. https://doi.org/ 10.1007/s10508-009-9574-7.

2. Grant JE, Pinto A, Gunnip M, Mancebo MC, Eisen JL, Rasmussen SA. Sexual obsessions and clinical correlates in adults with obsessive-compulsive disorder. Compr Psychiatry. 2006;47(5):325-9. https://doi.org/10.1016/j.comppsych.2006. 01.007 .

3. Voon V, Napier TC, Frank MJ, Sgambato-Faure V, Grace AA, Rodriguez-Oroz M, et al. Impulse control disorders and levodopa-induced dyskinesias in Parkinson's disease: an update. Lancet Neurol. 2017;16(3):238-50. https://doi.org/10.1016/ s1474-4422(17)30004-2.

4. Moser C. Hypersexual disorder: just more muddled thinking. Arch Sex Behav. 2011;40(2):227-9. https://doi.org/10.1007/ s10508-010-9690-4 (author reply 31-2).

5. Kafka MP, Krueger RB. Response to Moser's (2010) critique of hypersexual disorder for DSM-5. Arch Sex Behav. 2011;40:231-2.

6. Bancroft J, Graham CA, Janssen E, Sanders SA. The dual control model: current status and future directions. J Sex Res. 2009;46(2-3):121-42. https://doi.org/10.1080/0022449090 2747222.909792907[pii].

7. Garcia FD, Thibaut F. Sexual addictions. Am J Drug Alcohol Abuse. 2010;36(5):254-60. https://doi.org/10.3109/00952990. 2010.503823.

8. Reid RC, Carpenter BN, Hook JN, Garos S, Manning JC, Gilliland R, et al. Report of findings in a DSM-5 field trial for hypersexual disorder. J Sex Med. 2012;9(11):2868-77. https://doi.org/ 10.1111/j.1743-6109.2012.02936.x.

9. Grant JE, Atmaca M, Fineberg NA, Fontenelle LF, Matsunaga $\mathrm{H}$, Janardhan Reddy YC, et al. Impulse control disorders and "behavioural addictions" in the ICD-11. World Psychiatry. 2014;13(2):125-7. https://doi.org/10.1002/wps.20115.

10. Kraus SW, Krueger RB, Briken P, First MB, Stein DJ, Kaplan MS, et al. Compulsive sexual behaviour disorder in the ICD-11. World Psychiatry. 2018;17(1):109-10. https://doi.org/10.1002/ wps.20499.

11. Kor A, Fogel Y, Reid RC, Potenza MN. Should hypersexual disorder be classified as an addiction?. Sex Addict Compulsivity. 2013;20(1-2):https://doi.org/10.1080/10720162.2013.768132

12. Schultz K, Hook JN, Davis DE, Penberthy JK, Reid RC. Nonparaphilic hypersexual behavior and depressive symptoms: a meta-analytic review of the literature. J Sex Marital Ther. 2014;40(6):477-87. https://doi.org/10.1080/0092623X.2013. 772551.

13. Kühn S, Gallinat J. Chapter three - neurobiological basis of hypersexuality. In: Zahr NM, Peterson ET, editors. International Review of Neurobiology. Academic Press; 2016. p. 67-83

14. Gola M, Potenza MN. The proof of the pudding is in the tasting: data are needed to test models and hypotheses related to compulsive sexual behaviors. Arch Sex Behav. 2018;47(5):1323-5. https://doi.org/10.1007/s10508-018-1167-x.

15. Walton MT, Bhullar N. Compulsive sexual behavior as an impulse control disorder: awaiting field studies data. Arch Sex Behav. 2018;47(5):1327-31. https://doi.org/10.1007/ s10508-018-1200-0.

16. Langstrom N, Hanson RK. High rates of sexual behavior in the general population: correlates and predictors. Arch Sex Behav. 2006;35(1):37-52. https://doi.org/10.1007/ s10508-006-8993-y.

17. Goldey KL, van Anders SM. Sexual thoughts: links to testosterone and cortisol in men. Arch Sex Behav. 2012;41(6):1461-70. https://doi.org/10.1007/s10508-011-9858-6.

18. Ragan PW, Martin PR. The psychobiology of sexual addiction. Sex Addict Compulsivity J Treat Prev. 2000;7(3):161-75.

19. Cunningham RL, Lumia AR, McGinnis MY. Androgen receptors, sex behavior, and aggression. Neuroendocrinology. 2012;96(2):131-40. https://doi.org/10.1159/000337663[pii].

20. Bancroft J. Biological factors in human sexuality. J Sex Res. 2002;39(1):15-21. https://doi.org/10.1080/00224490209552114.

21. Saleh FM, Berlin FS. Sex hormones, neurotransmitters, and psychopharmacological treatments in men with paraphilic disorders. J Child Sex Abus. 2003;12(3-4):233-53. https://doi.org/ 10.1300/J070v12n03_09.

22. Argiolas A, Melis MR. Neuropeptides and central control of sexual behaviour from the past to the present: a review. Prog Neurobiol. 2013;108:80-107. https://doi.org/10.1016/j.pneur obio.2013.06.006.

23. Bradford JM. The neurobiology, neuropharmacology, and pharmacological treatment of the paraphilias and compulsive sexual behaviour. Can J Psychiatry. 2001;46(1):26-34. https://doi.org/ 10.1177/070674370104600104.

24. Balercia G, Boscaro M, Lombardo F, Carosa E, Lenzi A, Jannini EA. Sexual symptoms in endocrine diseases: psychosomatic perspectives. Psychother Psychosom. 2007;76(3):134-40. https:// doi.org/10.1159/000099840.

25. Kraus SW, Voon V, Potenza MN. Neurobiology of compulsive sexual behavior: emerging science. Neuropsychopharmacology. 2016;41(1):385-6. https://doi.org/10.1038/npp.2015.300.

26. Sher L. Combined dexamethasone suppression-corticotropinreleasing hormone stimulation test in studies of depression, alcoholism, and suicidal behavior. ScientificWorldJournal. 2006;6:1398-404. https://doi.org/10.1100/tsw.2006.251.

27 Kakko J, von Wachenfeldt J, Svanborg KD, Lidstrom J, Barr CS, Heilig M. Mood and neuroendocrine response to a chemical stressor, metyrapone, in buprenorphine-maintained heroin dependence. Biol Psychiatry. 2008;63(2):172-7. https://doi. org/10.1016/j.biopsych.2007.05.001 (S0006-3223(07)00429-5 [pii]).

28 Koob GF, Buck CL, Cohen A, Edwards S, Park PE, Schlosburg $\mathrm{JE}$, et al. Addiction as a stress surfeit disorder. Neuropharmacology. 2014;76(Pt B):370-82. https://doi.org/10.1016/j.neuro pharm.2013.05.024 (S0028-3908(13)00238-4 [pii]).

29 Exton NG, Truong TC, Exton MS, Wingenfeld SA, Leygraf $\mathrm{N}$, Saller B, et al. Neuroendocrine response to film-induced sexual arousal in men and women. Psychoneuroendocrinology. 2000;25(2):187-99 (S0306453099000499 [pii]). 
30. Exton MS, Kruger TH, Bursch N, Haake P, Knapp W, Schedlowski M, et al. Endocrine response to masturbation-induced orgasm in healthy men following a 3-week sexual abstinence. World J Urol. 2001;19(5):377-82.

31. Harrison C, Ratcliffe JM, Mitchell M, Smith MA. Cortisol reactivity to psychosocial stress is greater in sexual risk takers. Health Psychol Behav Med. 2014;2(1):221-30. https://doi.org/ 10.1080/21642850.2014.889571889571[pii].

32.• Chatzittofis A, Arver S, Öberg K, Hallberg J, Nordström P, Jokinen J. HPA axis dysregulation in men with hypersexual disorder. Psychoneuroendocrinology. 2016;63:247-53. https://doi.org/10. 1016/j.psyneuen.2015.10.002 ([ThestudyreportsdysregulationoftheHPAaxisincompulsivesexualbehaviordisorder]).

33. Mann JJ, Currier D. A review of prospective studies of biologic predictors of suicidal behavior in mood disorders. Arch Suicide Res. 2007;11(1):3-16. https://doi.org/10.1080/1381111060 0993124 (X8535011621LV4R5 [pii]).

34. Coryell W, Schlesser M. The dexamethasone suppression test and suicide prediction. Am J Psychiatry. 2001;158(5):748-53.

35. Jokinen J, Carlborg A, Martensson B, Forslund K, Nordstrom AL, Nordstrom P. DST non-suppression predicts suicide after attempted suicide. Psychiatry Res. 2007;150(3):297-303. https:// doi.org/10.1016/j.psychres.2006.12.001 (S0165-1781(06)00374$\mathbf{X}$ [pii]).

36. Aaron M. The pathways of problematic sexual behavior: a literature review of factors affecting adult sexual behavior in survivors of childhood sexual abuse. Sex Addict Compuls. 2012;19(3):199-218. https://doi.org/10.1080/10720162.2012. 690678.

37. Wilson HW, Widom CS. An examination of risky sexual behavior and HIV in victims of child abuse and neglect: a 30-year follow-up. Health Psychol. 2008;27(2):149-58. https://doi.org/ 10.1037/0278-6133.27.2.149 (2008-03424-003[pii]).

38 Heim C, Nemeroff CB. The role of childhood trauma in the neurobiology of mood and anxiety disorders: preclinical and clinical studies. Biol Psychiatry. 2001;49(12):1023-39 (S000632230101157X [pii]).

39. Teicher MH, Samson JA. Childhood maltreatment and psychopathology: a case for ecophenotypic variants as clinically and neurobiologically distinct subtypes. Am J Psychiatry. 2013;170(10):1114-33. https://doi.org/10.1176/appi.ajp.2013. 12070957.

40 McGowan PO, Sasaki A, D’Alessio AC, Dymov S, Labonte B, Szyf M, et al. Epigenetic regulation of the glucocorticoid receptor in human brain associates with childhood abuse. Nat Neurosci. 2009;12(3):342-8. https://doi.org/10.1038/nn.2270 (nn.2270 [pii]).

41.• Jokinen J, Bostrom AE, Chatzittofis A, Ciuculete DM, Oberg KG, Flanagan JN, et al. Methylation of HPA axis related genes in men with hypersexual disorder. Psychoneuroendocrinology. 2017;80:67-73. https://doi.org/10.1016/j.psyneuen.2017. 03.007 ([ThestudyreportsepigeneticchangesassociatedwiththeHPAaxisgenes,incompulsivesexualbehaviordisor der]).

42. Zorrilla EP, Logrip ML, Koob GF. Corticotropin releasing factor: a key role in the neurobiology of addiction. Front Neuroendocrinol. 2014;35(2):234-44. https://doi.org/10.1016/j.yfrne. 2014.01.001.

43. McFalls AJ, Imperio CG, Bixler G, Freeman WM, Grigson PS, Vrana KE. Reward devaluation and heroin escalation is associated with differential expression of CRF signaling genes. Brain Res Bull. 2016;123:81-93. https://doi.org/10.1016/j.brainresbu 11.2015.11.009.

44 Jordan K, Fromberger P, Stolpmann G, Muller JL. The role of testosterone in sexuality and paraphilia-a neurobiological approach. Part I: testosterone and sexuality. J Sex Med.
2011;8(11):2993-3007. https://doi.org/10.1111/j.1743-6109. 2011.02394.x.

45. Ciocca G, Limoncin E, Carosa E, Di Sante S, Gravina GL, Mollaioli $\mathrm{D}$, et al. Is testosterone a food for the brain? Sex Med Rev. 2016;4(1):15-25. https://doi.org/10.1016/j.sxmr.2015.10.007.

46. Rupp HA, Wallen K. Relationship between testosterone and interest in sexual stimuli: the effect of experience. Horm Behav. 2007;52(5):581-9. https://doi.org/10.1016/j.yhbeh.2007.07.015.

47. Stoleru SG, Ennaji A, Cournot A, Spira A. LH pulsatile secretion and testosterone blood levels are influenced by sexual arousal in human males. Psychoneuroendocrinology. 1993;18(3):205-18.

48. Huo S, Scialli AR, McGarvey S, Hill E, Tugertimur B, Hogenmiller A, et al. Treatment of men for "low testosterone": a systematic review. PLoS One. 2016;11(9):e0162480. https://doi. org/10.1371/journal.pone.0162480.

49. Turner D, Briken P. Treatment of paraphilic disorders in sexual offenders or men with a risk of sexual offending with luteinizing hormone-releasing hormone agonists: an updated systematic review. J Sex Med. 2018;15(1):77-93. https://doi.org/ 10.1016/j.jsxm.2017.11.013.

50. Wong JS, Gravel J. Do Sex offenders have higher levels of testosterone? Results from a meta-analysis. Sex Abuse. 2016. https://doi.org/10.1177/1079063216637857.

51 Jordan K, Fromberger P, Stolpmann G, Muller JL. The role of testosterone in sexuality and paraphilia-a neurobiological approach. Part II: testosterone and paraphilia. J Sex Med. 2011;8(11):3008-29. https://doi.org/10.1111/j.1743-6109. 2011.02393.x.

52. Chatzittofis A, Savard J, Arver S, Oberg KG, Hallberg J, Nordstrom $\mathrm{P}$, et al. Interpersonal violence, early life adversity, and suicidal behavior in hypersexual men. J Behav Addict. 2017;6(2):187-93. https://doi.org/10.1556/2006.6.2017.027.

$53 . \bullet$ Chatzittofis A, Boström AE, Öberg KG, Flanagan JN, Schiöth $\mathrm{HB}$, Arver S, et al. Normal testosterone but higher luteinizing hormone plasma levels in men with hypersexual disorder. Sex Med. 2020;8(2):243-50. https://doi.org/10.1016/j.esxm.2020. 02.005 ([The article is important as is the first study on HPG axis, reporting on $\mathrm{LH}$ and testosterone in compulsive sexual behavior disorder])

54. Kalichman SC, Rompa D. Sexual sensation seeking and sexual compulsivity scales: reliability, validity, and predicting HIV risk behavior. J Pers Assess. 1995;65(3):586-601. https://doi. org/10.1207/s15327752jpa6503_16.

55. Montgomery-Graham S. Conceptualization and assessment of hypersexual disorder: a systematic review of the literature. Sex Med Rev. 2017;5(2):146-62. https://doi.org/10.1016/j.sxmr. 2016.11.001.

56. Carosa E, Benvenga S, Trimarchi F, Lenzi A, Pepe M, Simonelli $\mathrm{C}$, et al. Sexual inactivity results in reversible reduction of LH bioavailability. Int J Impot Res. 2002;14(2):93-9. https://doi.org/10.1038/sj.ijir.3900832 (discussion 100).

57. Kingston DA, Seto MC, Ahmed AG, Fedoroff P, Firestone $\mathrm{P}$, Bradford JM. The role of central and peripheral hormones in sexual and violent recidivism in sex offenders. J Am Acad Psychiatry Law. 2012;40(4):476-85.

58. Gaffney GR, Berlin FS. Is there hypothalamic-pituitarygonadal dysfunction in paedophilia? A pilot study. Br J Psychiatry. 1984;145:657-60.

59. Safarinejad MR. Treatment of nonparaphilic hypersexuality in men with a long-acting analog of gonadotropin-releasing hormone. J Sex Med. 2009;6(4):1151-64. https://doi.org/10. 1111/j.1743-6109.2008.01119.x.

60. Mehta PH, Welker KM, Zilioli S, Carre JM. Testosterone and cortisol jointly modulate risk-taking. Psychoneuroendocrinology. 2015;56:88-99. https://doi.org/10.1016/j.psyneuen.2015. 02.023 . 
61. Raisanen JC, Chadwick SB, Michalak N, van Anders SM. Average associations between sexual desire, testosterone, and stress in women and men over time. Arch Sex Behav. 2018;47(6):1613-31. https://doi.org/10.1007/ s10508-018-1231-6.

62. Chadwick SB, Burke SM, Goldey KL, van Anders SM. Multifaceted sexual desire and hormonal associations: accounting for social location, relationship status, and desire target. Arch Sex Behav. 2017;46(8):2445-63. https://doi.org/10.1007/ s10508-017-0959-8.

63 Bancroft J. The endocrinology of sexual arousal. J Endocrinol. 2005;186(3):411-27. https://doi.org/10.1677/joe.1.06233 (186/3/411 [pii]).

64 Heinrichs M, von Dawans B, Domes G. Oxytocin, vasopressin, and human social behavior. Front Neuroendocrinol. 2009;30(4):548-57. https://doi.org/10.1016/j.yfrne.2009.05. 005 (S0091-3022(09)00029-6 [pii]).

65. Burri A, Heinrichs M, Schedlowski M, Kruger TH. The acute effects of intranasal oxytocin administration on endocrine and sexual function in males. Psychoneuroendocrinology. 2008;33(5):591-600. https://doi.org/10.1016/j.psyneuen.2008. 01.014.

66. Ross HE, Young LJ. Oxytocin and the neural mechanisms regulating social cognition and affiliative behavior. Front Neuroendocrinol. 2009;30(4):534-47. https://doi.org/10.1016/j.yfrne.2009. 05.004 .

67. Sanna F, De Luca MA. The potential role of oxytocin in addiction: what is the target process? Curr Opin Pharmacol. 2021;58:8-20. https://doi.org/10.1016/j.coph.2021.03.002.

68 Argiolas A. Oxytocin stimulation of penile erection. Pharmacology, site, and mechanism of action. Ann N Y Acad Sci. 1992;652:194-203. https://doi.org/10.1111/j.1749-6632.1992. tb34355.x.

69. Melis MR, Argiolas A, Gessa GL. Oxytocin-induced penile erection and yawning: site of action in the brain. Brain Res. 1986;398(2):259-65. https://doi.org/10.1016/0006-8993(86) 91485-x.

70. Yanagimoto M, Honda K, Goto Y, Negoro H. Afferents originating from the dorsal penile nerve excite oxytocin cells in the hypothalamic paraventricular nucleus of the rat. Brain Res. 1996;733(2):292-6. https://doi.org/10.1016/0006-8993(96) 00800-1.

71. Thackare H, Nicholson HD, Whittington K. Oxytocin-its role in male reproduction and new potential therapeutic uses. Hum Reprod Update. 2006;12(4):437-48. https://doi.org/10.1093/ humupd/dmk002.

72. Carmichael MS, Warburton VL, Dixen J, Davidson JM. Relationships among cardiovascular, muscular, and oxytocin responses during human sexual activity. Arch Sex Behav. 1994;23(1):59-79. https://doi.org/10.1007/bf01541618.

73. Murphy MR, Checkley SA, Seckl JR, Lightman SL. Naloxone inhibits oxytocin release at orgasm in man. J Clin Endocrinol Metab. 1990;71(4):1056-8. https://doi.org/10.1210/ jcem-71-4-1056.

74.•• Boström AE, Chatzittofis A, Ciuculete DM, Flanagan JN, Krattinger R, Bandstein M, et al. Hypermethylation-associated downregulation of microRNA-4456 in hypersexual disorder with putative influence on oxytocin signalling: a DNA methylation analysis of miRNA genes. Epigenetics. 2020;15(1-2):145-60. https://doi.org/10.1080/15592294.2019.1656157 ([Epigeneticfindingsfromthisstudysuggest theinvolvementoftheoxytocinergicsystemincompulsivesexualbehaviordisorder]).
75. Jurek B, Slattery DA, Hiraoka Y, Liu Y, Nishimori K, Aguilera $\mathrm{G}$, et al. Oxytocin regulates stress-induced $\mathrm{Crf}$ gene transcription through CREB-regulated transcription coactivator 3. J Neurosci. 2015;35(35):12248-60. https://doi.org/10.1523/jneurosci.134514.2015.

76. Ditzen B, Schaer M, Gabriel B, Bodenmann G, Ehlert U, Heinrichs $\mathrm{M}$. Intranasal oxytocin increases positive communication and reduces cortisol levels during couple conflict. Biol Psychiatry. 2009;65(9):728-31. https://doi.org/10.1016/j.biopsych.2008. 10.011 .

77. Cardoso C, Ellenbogen MA, Orlando MA, Bacon SL, Joober R. Intranasal oxytocin attenuates the cortisol response to physical stress: a dose-response study. Psychoneuroendocrinology. 2013;38(3):399-407. https://doi.org/10.1016/j.psyneuen.2012. 07.013 .

78. Carson DS, Hunt GE, Guastella AJ, Barber L, Cornish JL, Arnold JC, et al. Systemically administered oxytocin decreases methamphetamine activation of the subthalamic nucleus and accumbens core and stimulates oxytocinergic neurons in the hypothalamus. Addict Biol. 2010;15(4):448-63. https://doi.org/ 10.1111/j.1369-1600.2010.00247.x.

79. Pedersen CA, Smedley KL, Leserman J, Jarskog LF, Rau SW, Kampov-Polevoi A, et al. Intranasal oxytocin blocks alcohol withdrawal in human subjects. Alcohol Clin Exp Res. 2013;37(3):484-9. https://doi.org/10.1111/j.1530-0277.2012. 01958.x.

80. Walum H, Lichtenstein P, Neiderhiser JM, Reiss D, Ganiban JM, Spotts EL, et al. Variation in the oxytocin receptor gene is associated with pair-bonding and social behavior. Biol Psychiatry. 2012;71(5):419-26. https://doi.org/10.1016/j.biopsych.2011.09. 002.

81. Young LJ, Wang Z. The neurobiology of pair bonding. Nat Neurosci. 2004;7(10):1048-54. https://doi.org/10.1038/nn1327.

82. Bertsch K, Schmidinger I, Neumann ID, Herpertz SC. Reduced plasma oxytocin levels in female patients with borderline personality disorder. Horm Behav. 2013;63(3):424-9. https://doi. org/10.1016/j.yhbeh.2012.11.013S0018-506X(12)00285-1[pii].

83. Herpertz SC, Bertsch K. A new perspective on the pathophysiology of borderline personality disorder: a model of the role of oxytocin. Am J Psychiatry. 2015;172(9):840-51. https://doi.org/ 10.1176/appi.ajp.2015.15020216.

84. López HH. Cannabinoid-hormone interactions in the regulation of motivational processes. Horm Behav. 2010;58(1):100-10. https://doi.org/10.1016/j.yhbeh.2009.10.005.

85. Cota $D$. The role of the endocannabinoid system in the regulation of hypothalamic-pituitary-adrenal axis activity. J Neuroendocrinol. 2008;20(Suppl 1):35-8. https://doi.org/10.1111/j.13652826.2008.01673.x.

86 Murphy LL, Muñoz RM, Adrian BA, Villanúa MA. Function of cannabinoid receptors in the neuroendocrine regulation of hormone secretion. Neurobiol Dis. 1998;5(6 Pt):432-46. https:// doi.org/10.1006/nbdi.1998.0224.

87. Yee A, Loh HS, Ong TA, Ng CG, Sulaiman AH. Randomized, double-blind, parallel-group, placebo-controlled trial of bupropion as treatment for methadone-emergent sexual dysfunction in men. Am J Mens Health. 2018;12(5):1705-18. https://doi.org/ $10.1177 / 1557988318784152$.

88. Raymond NC, Grant JE, Kim SW, Coleman E. Treatment of compulsive sexual behaviour with naltrexone and serotonin reuptake inhibitors: two case studies. Int Clin Psychopharmacol. 2002;17(4):201-5. https://doi.org/10.1097/00004850-20020 7000-00008. 
89. Bostwick JM, Bucci JA. Internet sex addiction treated with naltrexone. Mayo Clin Proc. 2008;83(2):226-30. https://doi.org/10. 4065/83.2.226.

90.• Savard J, Öberg KG, Chatzittofis A, Dhejne C, Arver S, Jokinen J. Naltrexone in compulsive sexual behavior disorder: a feasibility study of twenty men. J Sex Med. 2020;17(8):1544-52. https:// doi.org/10.1016/j.jsxm.2020.04.318 ([Thearticleisimportantasitisthelargeststudyusinganopioidreceptorantagonist,naltrex one,forthetreatmentofcompulsivesexualbehaviordisorder]).

Publisher's Note Springer Nature remains neutral with regard to jurisdictional claims in published maps and institutional affiliations. 